\title{
Dielectric Properties of Ferroelectric Liquid Crystals with Diversified Molecular Structure ERRATUM
}

\author{
J.M. Czerwiec ${ }^{a}$, R. DAzBrowski ${ }^{b}$, M. ŻUrowska $^{b}$, D. Ziobro ${ }^{b}$ And S. Wróbel $^{a}$ \\ ${ }^{a}$ Institute of Physics, Jagiellonian University, Reymonta 4, 30-059 Cracow, Poland \\ ${ }^{b}$ Institute of Chemistry, Military University of Technology, S. Kaliskiego 2, 00-908 Warsaw, Poland
}

PACS numbers: 99.10.Cd

On the title page the Author Dorota Ziobro with the affiliation: Institute of Chemistry, Military University of Technology, 2 S. Kaliskiego str., 00-908 Warsaw, Poland should be added.
One of the Authors (J.M.C.) would like to apologize for omitting Her name, whose work contributed significantly to the emergence of this article. 